\title{
A preliminary spatial-temporal study of some soil characteristics in the calcareous massif of Sicó, Portugal
}

\author{
Maria Odete Torres, ${ }^{1,2}$ Maria Manuela Neves ${ }^{1,3}$ \\ ${ }^{1}$ Institute of Agronomy, University of Lisbon, Lisbon; ${ }^{2}$ Linking Landscape, Environment, \\ Agriculture and Food, Institute of Agronomy, University of Lisbon, Lisbon; ${ }^{3}$ Center of \\ Statistics and Applications, Faculty of Sciences, University of Lisbon, Lisbon, Portugal
}

\begin{abstract}
The mountainous massif of Sicó, in the centre of Portugal, is an extensive area composed of calcareous Jurassic formations. Hillside calcareous soils, with high $\mathrm{pH}$, present chemical restrictions to support plant growth and are subjected to important erosion processes leading to their degradation if not protected by vegetation. In a first year of study some soil physicochemical characteristics have been measured in some geo-referenced locations of a larger design experiment and an exploratory spatial analysis has been performed. The objective of this study was to present some suggestions in order to give sustainable phosphorus fertiliser recommendations aiming to establish pastures in these soils and thus support traditional livestock activity. Ten years apart, those soil characteristics have been measured again in the same locations and comparisions have been made. The objective was to understand the variability of the soil properties under study in order to better adequate the fertiliser soil management regarding the area restoration.
\end{abstract}

\section{Introduction}

The mountainous massif of Sicó, with a maximum altitude of 553 $\mathrm{m}$, is an extensive area of 50,000 ha composed of calcareous Jurassic formations. Hillside soils are shallow, poor, and subjected to important erosion processes showing a high level of degradation, if not protected by vegetation. Natural low productivity pastures support flocks of sheep. Their milk is used to produce a traditional cheese, the Queijo Rabaçal.

The introduction of sown pastures in these soils can be an important step towards soil restoration, protection and to support traditional and extensive livestock activity, representing an important element for humanisation of the landscapes in less developed areas. Calcareous grasslands are considered as biodiversity hotspots in Europe, harbouring a high diversity of both plant species and insect species, and have suffered an important decline during the last century (Piqueray and Mahy, 2010). In this context, their restoration has been promoted as a conservative strategy.

Calcareous soils present several restrictions to plant growth, namely high $\mathrm{pH}$, low levels of organic matter (OM), and low phosphorus availability. Phosphorus is one of the most limiting mineral nutrients for plant production and in calcareous soils is firmly bound due to precipitation with calcium ions (Hinsinger, 2001). Soil OM plays an important role in soil fertility, productivity, resilience to erosion and sustainability of agricultural and non-agricultural ecosystems (Craswell and Lefroy, 2001).

First data of some soil physicochemical characteristics such as pH, OM, available phosphorus and exchangeable calcium were collected in 1988 in locations defined in a larger experimental design. It is known that environmental data often present both a spatial structure, determined by the locations and a temporal one determined by the time period in which observations are taken at these locations. So, using classical geostatistical methods (Cressie, 1993; Goovaerts, 1997; Diggle et al., 1998), the spatial dependency level of those soil attributes was analysed. An exploratory statistical analysis was made in order to address the spatial autocorrelation in the data and to analyse the spatial variability. First each variable was analysed separately and the dependence structure of the data was modeled. Their kriged maps have been also generated. Some results were shown in Torres et al. (2011). Sustainable fertiliser recommendations to sown pastures were given according to the predictions of those soil properties all over the area under study.

Ten years apart, in 1998, observations of the same characteristics in the same locations have been registered. Comparisons were established and conclusions were drawn. A more ambitious study is however our objective: to use data collected over several years and to be able to decide what should be improved regarding the area restoration. 


\section{Materials and Methods}

The study area, about $900 \mathrm{~m}^{2}\left(39^{\circ} 53^{\prime} \mathrm{N}\right.$ and $\left.8^{\circ} 22^{\prime} \mathrm{W}\right)$, is located in the mountainous massif of Sicó in the centre of Portugal (Figure 1). The experimental field, a sown pasture consisting of subterranean clover (Trifolium brachycalycinum), gama medic (Medicago rugosa), strawberry clover (Trifolium fragiferum), perennial ryegrass (Lolium perenne) and cocksfoot (Dactylis glomerata) was divided into a grid of 60 cells. Each cell of the grid was a rectangule with $15 \mathrm{~m}^{2}(2.0 \mathrm{~m} \times 7.5 \mathrm{~m})$. In the centre of each cell a composite soil sample was randomly taken. In the 60 locations, four variables were measured: soil $\mathrm{pH}$, soil $\mathrm{OM}$, soil available phosphorus $\left(\mathrm{P}_{2} \mathrm{O}_{5}\right)$ and soil exchangeable calcium (Ca). Data from those variables in the same locations were collected in two years 1988 and 1998 .

For those data an exploratory analysis was performed using the $\mathrm{R}$ environment (R Development Core Team, 2012), where many packages are available for the analysis of spatial data. Classical geostatistical methods (Cressie, 1993; Goovaerts, 1997; Diggle et al., 1998) were used to address spatial dependency and to perform kriged values for those variables in locations no observed. In the second year of study (1998) a similar analysis was first performed. Comparison between the two dates was done through statistical tests using the idea proposed by Dale and Fortin (2009) for correlation tests. They proposed a correction for correlation tests considering the sample size $n$ for the t-Student test replaced at a sample size that accounted for the spatial autocorrelation.

\section{Results and Discussion}

Location of each sample point as well as the relative size of observed values, in 1988, for each variable are plotted in Figure 2.

Descriptive statistics were calculated and normality tests were performed leading to the following remarks: distribution of $\mathrm{pH}$ was skewed, with the presence of outliers, showing a strong departure from the normality (Shapiro-test $\mathrm{P}=1.424 \times 10^{-6}$ ). Soil $0 \mathrm{M}$, with strong concentration of high values was also skewed and revealed a high variability. Soil available phosphorus, $\mathrm{P}_{2} \mathrm{O}_{5}$, presented the highest dispersion, as well as a non-normal behaviour (Shapiro-test $\mathrm{P}=0.001421$ ).

Figure 2 displays the observed values of each variable enhancing their relative amount. It shows that lower soil phosphorus contents are present with greater levels of calcium, as a result of the formation of low solubility calcium phosphates, reducing the nutrient availability to plants. Lower values of soil $\mathrm{pH}$ are observed with increasing soil organic matter as a result of its buffering capacity.

Figure 3 represents the experimental semivariograms and the fitted theoretical semivariograms for the variables under study. It shows that a dependence structure exists for all the soil characteristics in the area

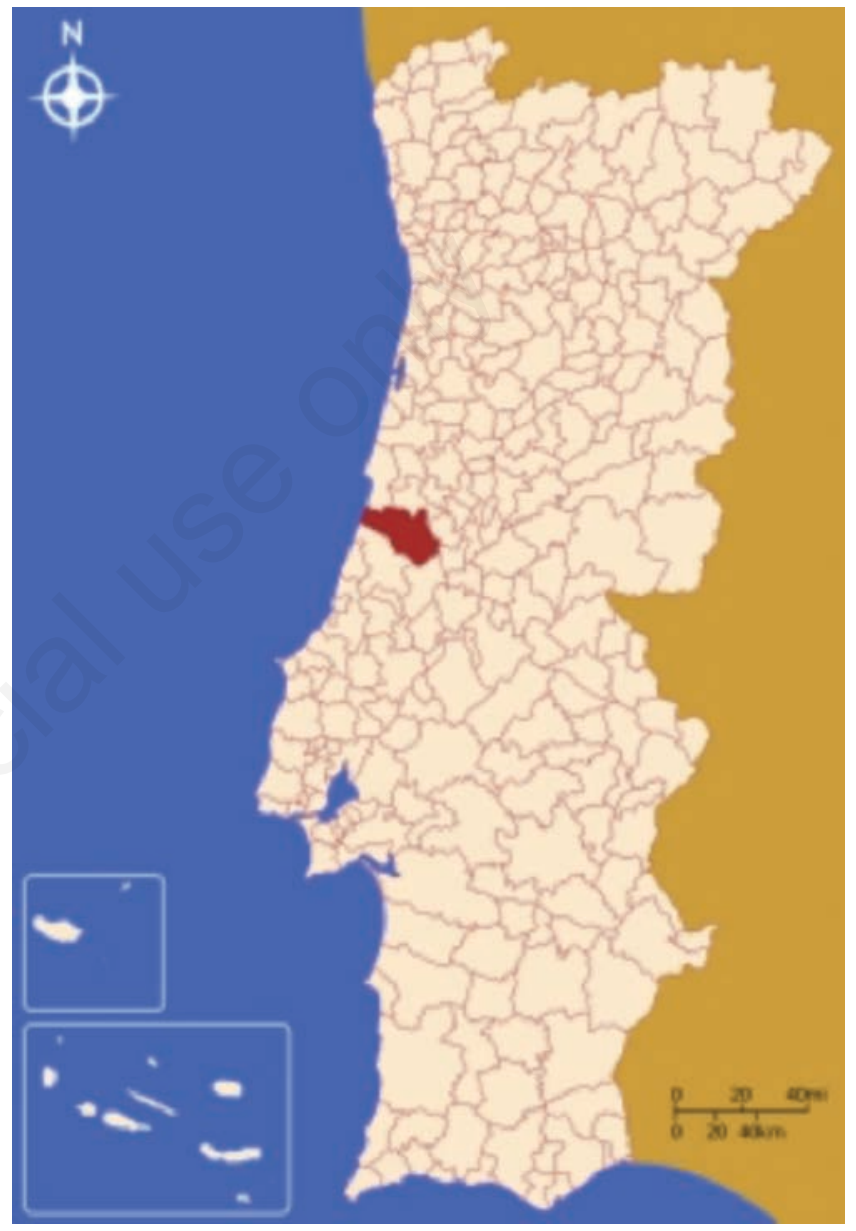

Figure 1. Location of calcareous massif of Sicó, Portugal.

Table 1. Summary statistics of each of soil variable observed.

\begin{tabular}{|c|c|c|c|c|c|c|c|c|}
\hline & \multicolumn{2}{|c|}{$\mathrm{pH}$} & \multicolumn{2}{|c|}{ OM $(\%)$} & \multicolumn{2}{|c|}{$\mathrm{P}_{2} \mathrm{O}_{5}(\mathrm{mg} / \mathrm{kg})$} & \multicolumn{2}{|c|}{$\mathrm{Ca}\left(\mathrm{cm}_{(+)} / \mathrm{kg}\right)$} \\
\hline & 1988 & 1998 & 1988 & 1998 & 1988 & 1998 & 1988 & 1998 \\
\hline Mean & 8.18 & 8.35 & 1.72 & 2.34 & 17.32 & 44.27 & 11.18 & 12.43 \\
\hline SD & 0.07 & 0.07 & 0.30 & 0.40 & 4.00 & 22.40 & 1.56 & 2.18 \\
\hline Median & 8.20 & 8.35 & 1.76 & 2.30 & 17.50 & 40.00 & 11.28 & 12.53 \\
\hline Minimum & 8.09 & 8.20 & 0.95 & 1.31 & 9.00 & 11.00 & 7.99 & 7.85 \\
\hline Maximum & 8.50 & 8.50 & 2.19 & 3.22 & 25.00 & 93.00 & 15.09 & 17.01 \\
\hline CV (\%) & 0.80 & 0.78 & 17.52 & 17.30 & 23.11 & 50.59 & 13.96 & 17.53 \\
\hline Skew & 1.75 & 0.12 & -0.44 & -0.14 & -0.30 & 0.47 & 0.19 & -0.19 \\
\hline Kurt & 6.72 & -0.31 & -0.50 & -0.19 & -0.67 & -0.91 & -0.42 & -0.60 \\
\hline
\end{tabular}

OM, organic matter; SD, standard deviation; $\mathrm{CV}$, coefficient of variation. 
under study, although $\mathrm{pH}$ and $\mathrm{OM}$ show that for locations about 10/12 meters apart no correlation seems to be observed. The theoretical models chosen in Figure 3 were considered for obtaining kriged surfaces. Predicted values for $\mathrm{Ca}, 0 \mathrm{M}, \mathrm{pH}$ and $\mathrm{P}_{2} \mathrm{O}_{5}$ are shown in Figure 4, obtained by kriging with the information of the semivariogram models defined above and after defining a grid over the region. For the data collected in 1998 , the same statistical analysis was performed. Figure 5 shows the relative size of values of the same characteristics, in each location, collected in 1998.

Table 1 shows the summary statistics for both years under study. In this exploratory analysis $\mathrm{OM}$ and $\mathrm{P}_{2} \mathrm{O}_{5}$ presented a different behaviour from that showed ten years before. Normality tests and semivariogram models were also performed.

Comparison between the two dates was done through statistical tests using the idea proposed by Dale and Fortin (2009) for correla- tion tests. The tests performed have shown for $0 \mathrm{M}$ and $\mathrm{P}_{2} \mathrm{O}_{5}$ significantly higher values $(\mathrm{P}<0.01)$ in 1998 than in 1988. The classical t-tests, applied when observations are collected in an independent context not verified here, should not be used. However, given the weak spatial dependence, the same conclusions have been obtained when using these tests.

The improvement in soil phosphorus availability through fertilisation led to a better establishment of the sown pasture species, especially legumes. In addition, the increase in soil nitrogen through symbiotic $\mathrm{N}_{2}$ fixation by pasture legumes stimulated grasses growth. As a result of a greater biomass accumulation, soil organic matter increased, after the decomposition of plant parts namely roots or falling leaves. This is in accordance with the objective of soil protection and restoration and the consequent promotion of livestock activity in the region.
pH

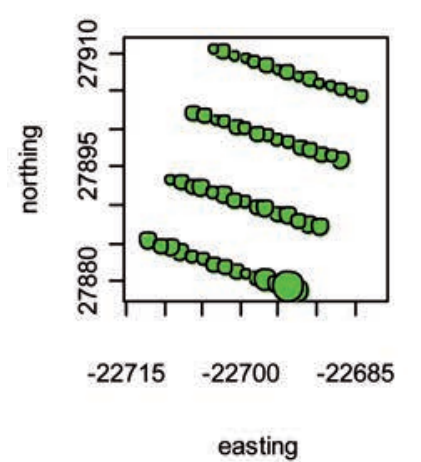

OM

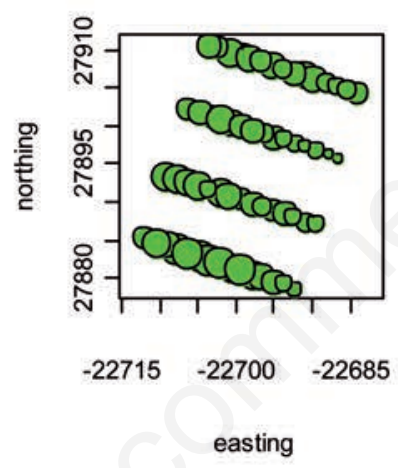

P205

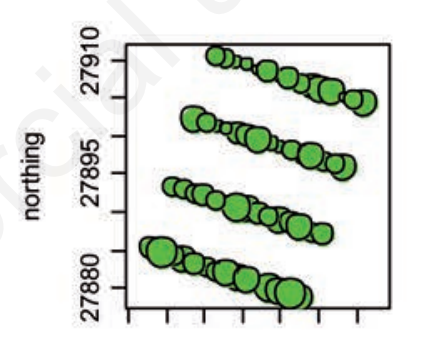

$-22715 \quad-22700 \quad-22685$
$\mathrm{Ca}$

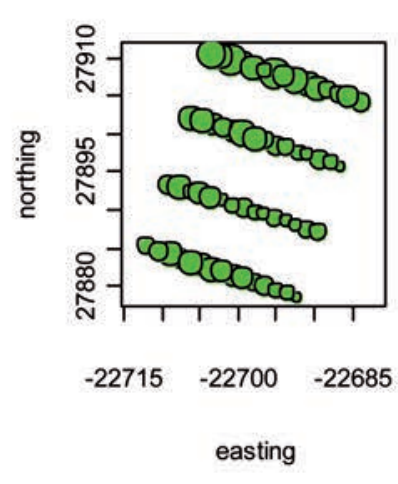

Figure 2. Location and relative size of observed values for each variable at sampling points (data collected in 1988).
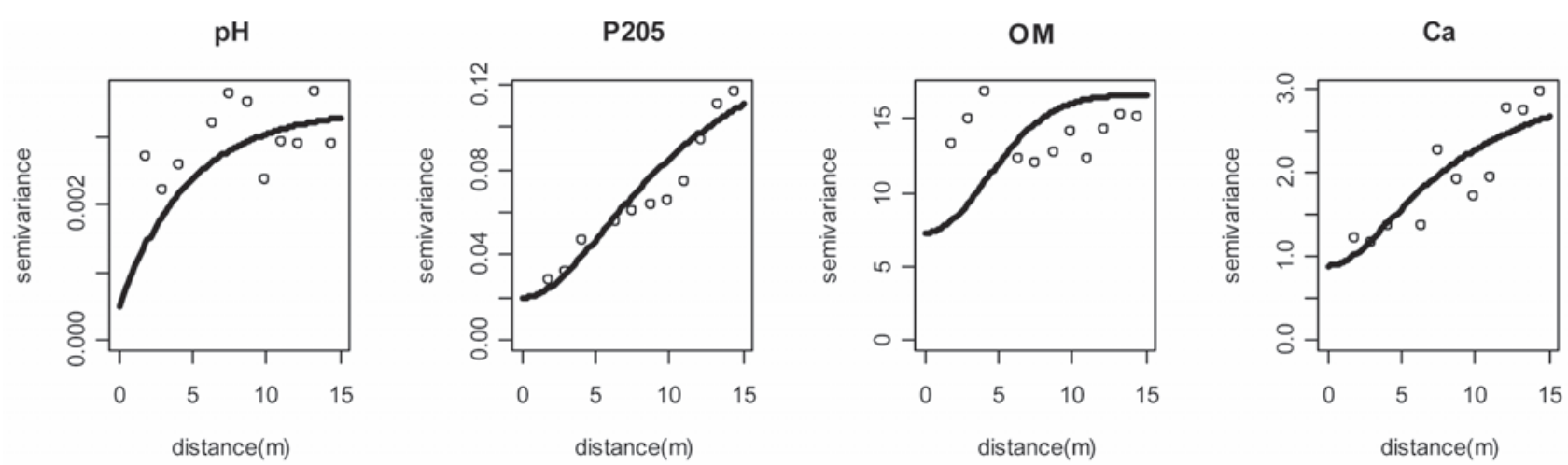

Figure 3. Experimental semivariograms and the fitted theoretical semivariograms for each variable. 


\section{Conclusions}

This is a study that is still in progress. Geostatistics analysis was considered and empirical semivariograms were calculated to characterise the spatial dependence pattern for each variable. With this information, predicted values were obtained in locations not observed, and fertiliser recommendations were given and applied to the locations suggested by our previous study. More observations have been registered some years later and are now being analysed and compared in order to validate the present fertiliser recommendations.
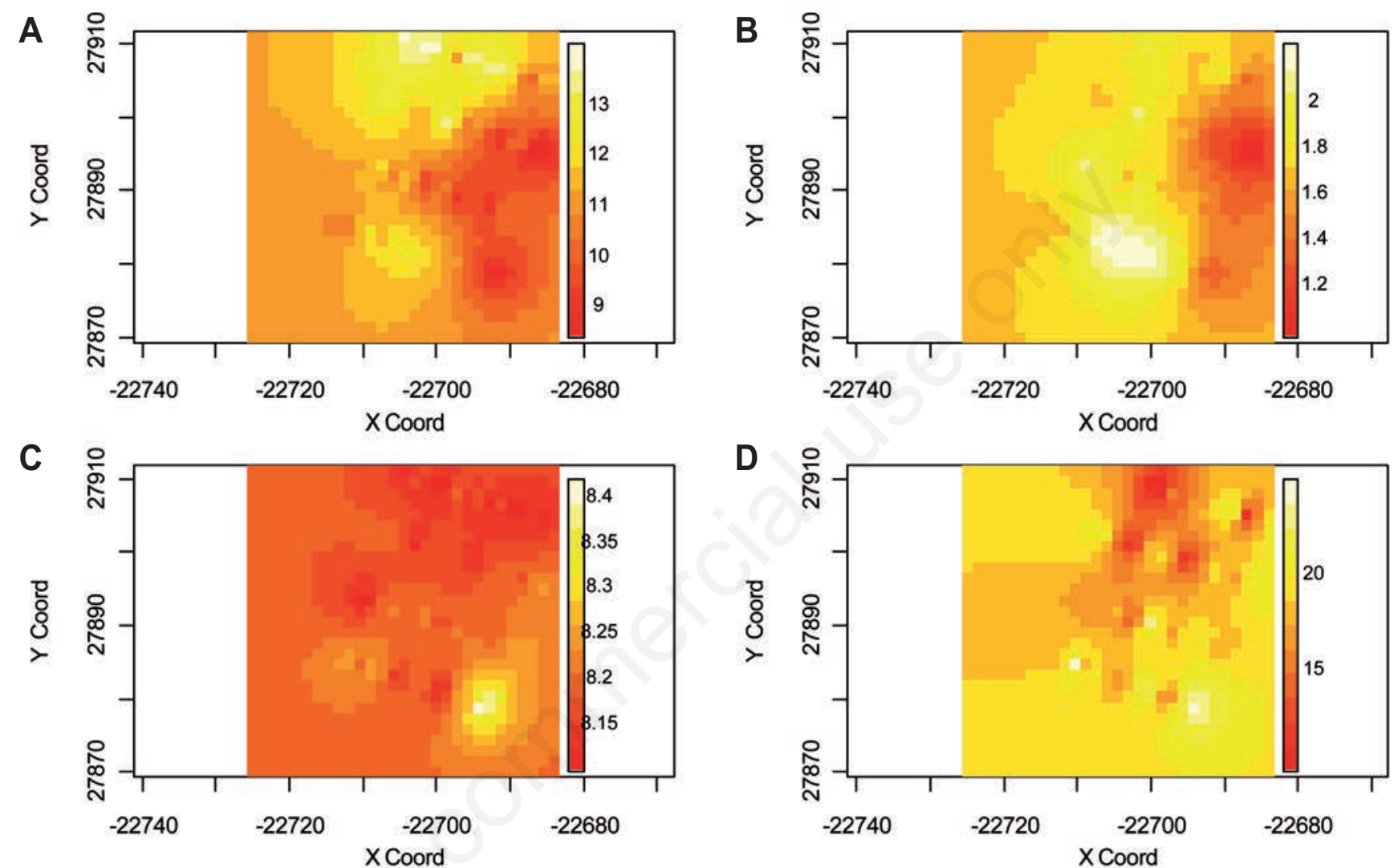

Figure 4. Kriged values for calcium and organic matter ( $\mathrm{A}$ and $\mathrm{B}$, respectively) and $\mathrm{pH}$ and $\mathrm{P}_{2} \mathrm{O}_{5}(\mathrm{C}$ and $\mathrm{D}$, respectively) in locations not observed.
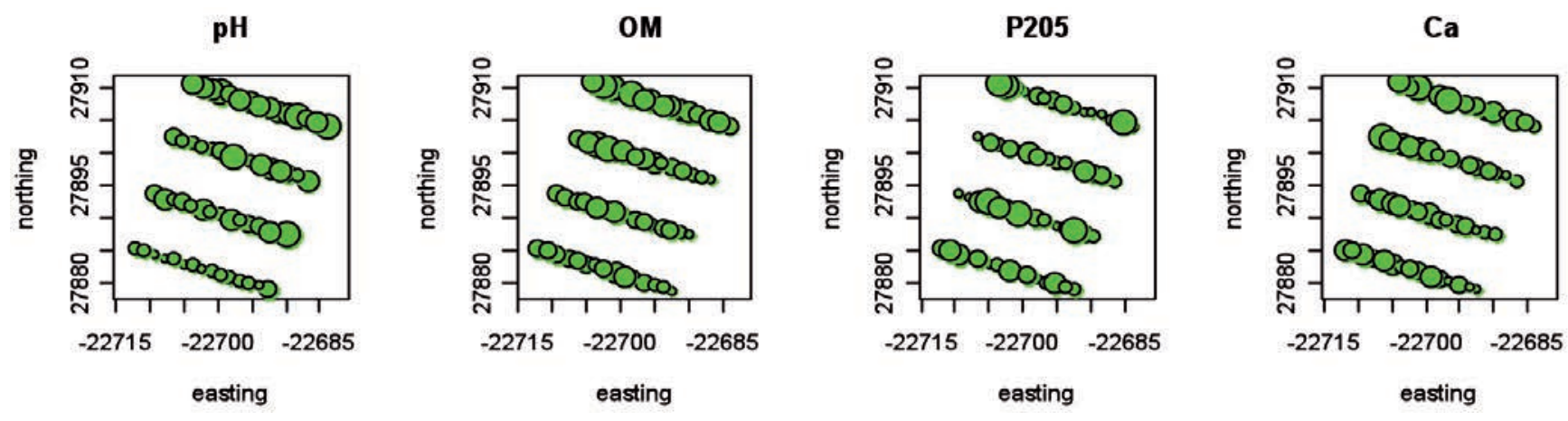

Figure 5. Location and relative amount of observed values for each variable at sampling points (data collected in 1998). 


\section{References}

Craswell ET, Lefroy RDB, 2001. The role and function of organic matter in tropical soils. Nutr Cycl Agroecosys 61:7-18.

Cressie N, 1993. Statistics for spatial data. John Wiley and Sons, New York, NY, USA.

Dale MRT, Fortin MJ, 2009. Spatial autocorrelation and statistical tests: some solutions. J Agr Biol Envir St 14:188-206.

Diggle PJ, Tawn JA, Moyeed RA, 1998. Model-based geostatistics. Appl Stat 473:299-350.

Goovaerts P, 1997. Geostatistics for natural resouces evaluation. Oxford Universiy Press, New York, NY, USA.

Hinsinger P, 2001. Bioavailability of soil organic P in the rhizosphere as affected by root-induced chemical changes: a review. Plant Soil 237:173-95.

Piqueray J, Mahy G, 2010. Revue bibliographique sur la restauration des pelouses calcicoles en Europe: contraintes rencontrées et solutions proposées. Biotechnol Agron Soc 14:471-84.

R Development Core Team, 2012. R: a language and environment for statistical omputing. R Foundation for Statistical Computing, Vienna, Austria. Available from: http://www.R-project.org

Torres MO, Neves MM, Prata Gomes D, 2011. Spatial analysis of some soil physicochemical properties in mountainous massif of Sicó, Portugal. Available from: https://aisberg.unibg.it/ retrieve/handle/ 10446/26459/ 6515/88.pdf 